\title{
A comprehensive approach to optimization of industrial enterprises management structure
}

\author{
Aleksey Salov ${ }^{1, *}$, Anna Gavrilova ${ }^{1}$, and Lyaisan Sagitova ${ }^{1}$ \\ ${ }^{1}$ Samara State Technical University, Samara, Russia
}

\begin{abstract}
The conditions of functioning of the power plants management systems are considered in the article. Comprehensive analysis of. The comprehensive analysis of the current and previously used management structures showed a variety of possible options for constructing them. There is proposed a set of partial criteria of the analyzed management structures grouped in local criteria that determine the features of the power plants functioning. Functions of local optimization criteria are identified. The formulated partial and local criteria of the management structures characterize balance, integrity, controllability, and stability of the analyzed control systems and in complex determine the effectiveness of the energy companies. Analysis of the performance of private structures analyzed showed that the assessment of the quality of the particular criteria give different, uncorrelated and conflicting results. It is necessary to develop methods of multi-criteria evaluation to get an unequivocal result of the system effectiveness of the analyzed management structures.
\end{abstract}

\section{Introduction}

Effective management of industrial plants, including power plants and systems is not possible if the control systems of the structure are not consistent with the objectives and tasks facing them, particularly nowadays - in the period of intense restructuring and reorganization processes to ensure successful entry into the market of [1-3].

During the transition period, the organization of production management system should be based on the concept of a complex approach, which means that the management of production should be based on holistic properties and patterns of behavior of companies that did not exist in its constituent parts [4-6].

While developing the methods and optimal control systems we should take into account the totality of energy, technological, economic, financial, institutional and other factors characterizing the specifics of the operation of the control object.

With the change of the goals of the companies, there should be changes in their management structure aimed at their effective independent functioning in the reformation conditions, ensuring the competitiveness of the company as a whole [4].

Based on system analysis methods there are studied several structures of power plants management systems to determine their compliance with the objectives and environmental factors in the current operating conditions using the generalized effectiveness criterion [7-11].

The analyzed structures include the one that operated until recently at the generating plants, and is used now with some internal changes.

\section{Description of the research object}

The object of this research work is the power station with co-generation (heat and power plant). It means the use of power station to generate electricity and useful heat at the same time for the needs of the industry of the region.

The company operates as a part of the energy company, which unites several similar power plants in the industrial region. The management system of power station is a hierarchical multi-level structure.

The CEO, director or chief engineer heads the company. The second level of management includes deputies they are decision makers, as well as the company CEO. First two levels approve the modes of functioning of the equipment, its repair or reservation periods. The second level include the positions listed below:

- Deputy Director for General Affairs (COO),

- Deputy Director of Economics (CFO),

- Deputy Director for Personnel and Social Affairs,

- Chief Engineer,

- Deputy Chief Engineer (Maintenance),

- Deputy Chief Engineer (Repairs),

- Legal Adviser,

- Inspector of orders execution control,

- Chief of administration.

The third level includes heads of various departments: heads of divisions, services and workshops. Such as:

- Human Resources Department,

- Maintenance department, 
- Planning and economic Department,

- Office Department,

- Department of capital construction,

- Finance Department,

- Accounting Department,

- Shift manager,

- Technical Engineering Department,

- Boiler Department,

- Turbine Department,

- Electric Department,

- Department of thermal automatics and measurements,

- Fuel-transport Department,

- Chemical Department,

- Shift supervisors,

- Repairs Department,

- Metals Laboratory,

- Mechanical repair shop,

- Repair and construction shop,

- Emergencies and Civil Defense Department,

- Labor protection Department.

Three-tier management structure is shown in Fig.1.

Prior to the restructuring of the economy, ie, until 1990 at power generating companies there operated typical management structure, since 2000 energetic enterprises management structure changed dramatically. The changes occurred in the direction of combining the functions of individual deputies, for example: Chief Engineer mixed with the position of director. Furthermore, the departments that did not directly relate to the production function of the enterprise, like repair services, were removed or reduced.

In our opinion, not all of the structural changes that took place at the enterprises provide the necessary reliability and continuity of the heat and electric energy supply in the emergencies during the heating season. Due to that, we created three more management structures, which are considered in the article.

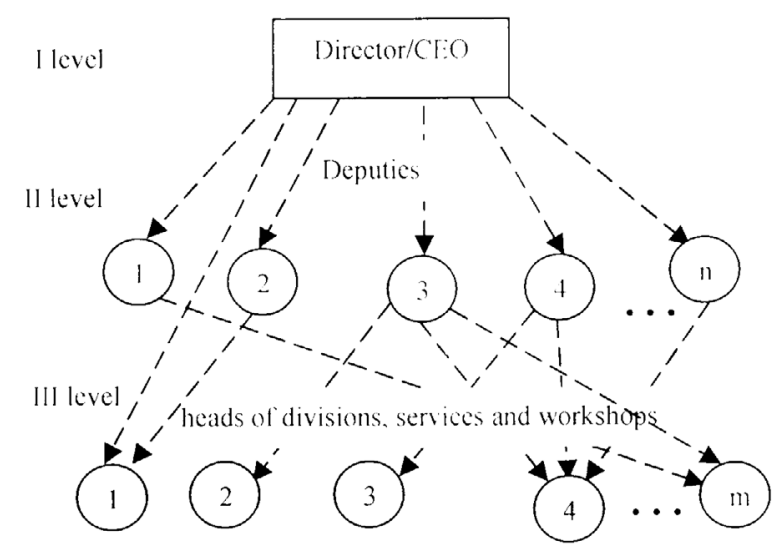

Fig. 1. Scheme of the enlarged management structure of the power plant.

\section{Determination of the criteria of assessment of the management structures}

System analysis of the structural management schemes is conducted using the methodology of graph theory. These indicators are used as local criteria of effectiveness of the analyzed management structures [1, $2]$.

- The balance of the structure;

- The integrity of the structure;

- Controllability of the structure;

- The structure stability.

A group of the partial criteria that are formulated further assesses each of the local criteria.

1. The balance of the structure

- Information load at the first level of management.

Information load at the highest level of the hierarchy - from the first head (director) - the value of the balance of the information traffic load among decision makers. When decision-makers have a large number of connections, there is an overload of information and the effectiveness of management decisions falls. In practice, it is widely used that a rational amount of information links for CEO is no more than seven.

- Information load at the second level of management.

The structure is also more balanced, if the load of the deputy heads - decision-makers - is balanced. It is possible in the case when each deputy would have approximately the same number of administrative relations, indicating the similarity of their traffic load.

Equability of the information load distribution among the managers of the first and the second levels

To improve the efficiency of the system it is necessary to seek to ensure that the information load is distributed evenly among all decision makers. It is normal for managerial functions at different levels of the management structure of the hierarchy to be materially different.

The analyzed structures differ in the number of deputy directors, directors of the company, the number of divisions and departments directly under each of the deputies and the Director himself.

2. The integrity of the structure

- The number of the structure centers.

Management decisions are made in the centers of the structure. In the analyzed structures, these centers are the director, chief engineer and deputy director of capital construction. There should be the smallest distance from these centers to the most remote departments and workshops. Based on the index of integrity and compactness of the structure of management, the most effective is the structure with the largest number of centers;

- The diameter of the structure.

The diameter of the management structure characterizes the compactness of the management structure - the shortest path connecting the two elements of the structure - for example the connection path between heads of divisions, services and workshops. The preferred structure should have the smallest diameter from the CEO to the second and third management levels. Compact and integrated structures are the ones with the shortest length between the management positions of the third level;

- The radius of the structure. 
Radius of the management structure describes the minimum length of administrative communications to the most distant elements of the organizational structure. The smaller radius the graph has, the higher is the compactness of the management structure.

3. The controllability of the structure

- The number of information channels.

The number of information channels through which management decisions are passed. The more channels, the more opportunities for the management has the appropriate structure. This number of information channels equals the number of lines that connect the various departments of administrative structures among themselves, with the deputy head and his deputies;

- the number of closed feedback loops that occur in the considered management structure. Obviously, the greater the number of closed circular information transfer cycles in the structure, the greater the controllability of the structure.

4. The controllability of the structure

- The stability of the management system is evaluated with the use of the following indicators:

- the structure is less stable, if it has a minimum number of persons taking management decisions, with the direct impact on all participants in the organizational structure. This partial criterion determines the amount of the main persons in the management structure who control all processes and events. The greater the number of such positions, the more stable and more reliable the structure. Otherwise, when management is provided by a small number of decision makers in the loss of control in parts of the processes situations, or in case of non-availability of one of the decision makers loss of control of the whole management structure may occur;

- the structure is internally stable if it has the maximum number of directly unrelated members of the organizational structure. The greater the number of positions with independence in making and implementing management decisions, the greater the stability of the management structure in cases of the loss of working capacity, or failure of individual elements of the structure.

Analysis of partial criteria characterizing the effectiveness of the systems shows that some of them have to take the maximum values, and the other - the minimum. Therefore, the most holistic structure is the one that has the greatest number of centers, but the smallest diameter and radius. Furthermore, it should have the greatest number of information channels, and of feedback loops to become more manageable.

It follows that the quality assessment of different management systems with the use of various partial criteria gives conflicting uncorrelated results.

It is necessary to develop methods of multi-criteria evaluation for unambiguous results of the analysis of the effectiveness of management structures [12-21].

\section{Conclusions}

1. Analysis of the management structures of power plants has shown a variety of possible options for their construction. It is impossible to make a definite conclusion on the conformity of one of the analyzed structures to the goals and challenges of the enterprises in terms of restructuring and competitiveness.

2. Local criteria that jointly characterize the efficiency of the analyzed management structures are formulated.

3. Partial criteria that convolute to the local criteria and their physical meaning are defined.

4. It was determined that the assessment of the quality of management structures with the use of various partial criteria gives different, uncorrelated and conflicting results.

5. It is necessary to develop methods of multi-criteria evaluation for unambiguous result of the research of the efficiency of the analyzed management structures.

\section{References}

1. A.G. Salov, Proceedings of the higher educational institutions of the North-Caucasian region. Technical science, 1(143), 32-37 (2008)

2. N.V. Diligensky, A.G. Salov, Bulletin of the Samara State Technical University. Tehnical science, (24), 17-25 (2009)

3. M.V. Posashkov, A.G. Salov, V.I. Nemchenko, Problems of Economics and Management of oil and gas complex, 1, 27-32 (2014)

4. A.A. Gavrilova, A.G. Salov, Russia, as a transforming society: economics, culture and management, 24-29 (2011)

5. V.I. Nechiporenko, Structural analysis systems (efficiency and reliability) (Soviet Radio, Moscow, 1977)

6. E.A. Matveeva, A.R. Diyazitdinova, O.N. Chernyh, A.A. Gavrilova, Design of complex business objects based on the system analysis: monograph (PGUTI, Samara, 2016)

7. N.V. Diligensky, A.A. Gavrilova, M.V. Tsapenko, Construction and identification of mathematical models of production systems: tutorial (OOO Etching, Samara, 2005)

8. A.A. Gavrilova, D.S. Kolmykov, A.A. Alpheus, Herald of the Samara State Technical University. A series of Engineering, 40, 155-162 (2006)

9. A.A. Gavrilova, A.G. Salov, V.K. Gavrilov, Herald of the Samara State Technical University. A series of Engineering, 2(22), 186-195 (2008)

10. A.A. Gavrilova, A.G. Salov, A.V. Kyhareva, J.V. Gavrilova, Herald of the Samara State Technical University. A series of Engineering, 3(31), 201-207 (2011)

11. A.A. Gavrilova, A.G. Salov, Industrial energetics, 12, 31-34 (2011)

12. F. Harari, Graph Theory (KomKniga, Moscow, 2006) 
13. N. Hibiki, Toshiyuki Sueyoshi, Omega, The International Journal of Management Science, 27, 139-153 (1999)

14. Th. Post, J. Spronk, European Journal of Operational Research, 115, 472-487 (1999)

15. A.D. Athanassopoulos, N. Lambroukos, L. Seiford, European Journal of Operational Research, 115, 413-428 (1999)

16. V.L. Arnold, I.R. Bardhan, W.W. Cooper, S.C. Kumbhakar, Annals of Operations Research 66, 996, 255-277, 9/25 9/27.

17. R.D. Banker, A. Charnes, W.W. Cooper, Omega, The International Journal of Management Science, 30, 9, 1078-1092 (1984)
18. A. Charnes, W.W. Cooper, E. Rhodes, European Journal of Operational Research, 2, 429-444 (1978)

19. A. Charnes, W.W. Cooper, A.Y. Lewin, L.M. Seiford, The DEA Process, Usages and Interpretations Data Envelopment Analysis: Theory, methodology and applications (Kluwer Academic Publishers, Boston 1994)

20. A.T. Sik, A. Charnes, W.W. Cooper, Managerial and Decision Economics, 9(3), 251-253 (1988)

21. Al-Faraj, N. Taqi, S. Abdulaziz Alidi, Khalid A. $\mathrm{Bu}-$ Bshait, International Journal of Operations and Production Management, 13(9), 45-52 (1993) 